induction and release. Seeley focuses attention on the endodormancy of woody species and stresses the point that in the absence of direct methods, indirect methods must be used to quantify seed dormancy. The immensity of the problem is clearly evident in the remark by Seeley "...in the obvious unknown ED (endodormancy) milieu, how can we measure its intensity, its transition and its release?" Fuchigami and Wisniewski emphasize the benefits of developing quantitative systems of classifying dormancy in buds. They present a conceptual numerical model based on growth stages divisible into numerical units that would likely lead to improved understanding and quantification of dormancy. Faust et al. discuss the roles of hormonal, chemical, and physical factors in bud dormancy, making a compelling argument for the role of bound vs. free water in the control of endodormancy. This article proposes several biochemical and physiological approaches for measuring dormancy.

The workshop was the first attempt at quantifying plant dormancy. It provided an excellent opportunity to review the state of our knowledge of plant dormancy, the differences and similarities in seed and bud dormancy, and the various approaches used to quantify them. The participants hope that it will serve as a forerunner for future workshops or colloquia for reporting progress in this important area of plant development.

\section{Literature Cited}

Goldmark, P.J., J. Curry, C.F. Morris, and M.K. Walker-Simmons. 1992. Cloning and expression of an embryo-specific mRNA up-regulated in hydrated dormant seeds. Plant Mol. Biol. 19:433-441.

Khan, A.A. 1975 . Primary, preventive and permissive roles of hormones in plant systems. Bot. Rev. 43:391-420.

Khan, A.A. 1996. Control and manipulation of seed dormancy, p. 29-45. In: G.A. Lang (ed.). Plant dormancy: Physiology, biochemistry and molecular biology. CAB Intl., Wallingford, U.K.

Khan, A.A. and C. Andreoli. 1993. Hormonal control of seed dormancy and germination under stressful and nonstressful conditions, p. 625-632. In: D. Come and F. Corbineau (eds.). Fourth Intl. Workshop on Seeds. Basic and applied aspects of seed biology. vol. 2. ASFIS, Paris, France.

Li, B. and M.E. Foley. 1995. Cloning and characterization of differentially expressed genes in imbibed dormant and afterripened Avena fatua embryos. Plant Mol. Biol. 29:823-831.

Stafstrom, J.P. and I.M. Sussex. 1993. Expression of a ribosomal protein gene in axillary buds of pea seedlings. Plant Physiol. 100:1494-1502.

Toyomasu, T., T. Yamaguchi, H. Yamane, N. Murofushi, and Y. Inoue. 1995. cDNA cloning and characterization of gibberellin-responsive genes in photoblastic lettuce seeds. Biosci. Biotech. Biochem. 59:1846-1849.

\title{
Quantification of Seed Dormancy: Physiological and Molecular Considerations
}

\author{
Anwar A. Khan \\ Department of Horticultural Sciences, New York State Agricultural Experiment Station, Cornell University, \\ Geneva, NY 14456
}

Physiological and biochemical controls needed to induce, maintain, and release seed dormancy are not clearly understood and hence it has been difficult to quantify dormancy. The studies on dormancy have dealt with the changes in embryo growth potential or germinability in relation to the controlling factors within the embryo, covering structures and environmental stimuli or their combinations in a doserelated fashion. More recently, attempts have been made to relate dormancy maintenance and release to temporal cellular and molecular changes, and conflicting theories or mechanisms for the control of dormancy have been advanced. This situation has made the task of quantifying dormancy quite difficult. For example, several genes or cDNA clones have been identified from dormant seeds and the temporal changes in the mRNA transcript levels of these genes during hydration, using labeled cDNA as a probe, have been studied. The transcript levels increase (Toyomasu et al., 1995) or decline and disappear (Goldmark et al., 1992; Li and Foley, 1995) in response to GA.

This article describes the various approaches that have been employed to quantify dormancy induction, maintenance, and release. They are based on the performance of seed in relation to the changes in the strength of the embryo covering structures, the effects of the environmental stimuli, responsiveness to hormones, hormone concentrations, RNA and protein synthesis, mRNA transcript levels of a cDNA clone, or combinations thereof.

\section{COVERING STRUCTURES AND EMBRYO GROWTH POTENTIAL}

Strength of covering structures and dormancy intensity. Indian ricegrass [Oryzopsis hymenoides (Roem. \& Shult.) Ricker] seeds have

Received for publication 1 July 1996. Accepted for publication 30 Nov. 1996. The cost of publishing this paper was defrayed in part by the payment of page charges. Under postal regulations, this paper therefore must be hereby marked advertisement solely to indicate this fact. seedcoat (lemma and palea) and embryo dormancy (McDonald and Khan, 1977). Increasing the period of scarification with sulfuric acid progressively increased the germination percentage. Germination percentage increased linearly with the increase in scarification time (Fig. 1). Younger seeds (1971 vs. 1970 harvest) were more resistant to

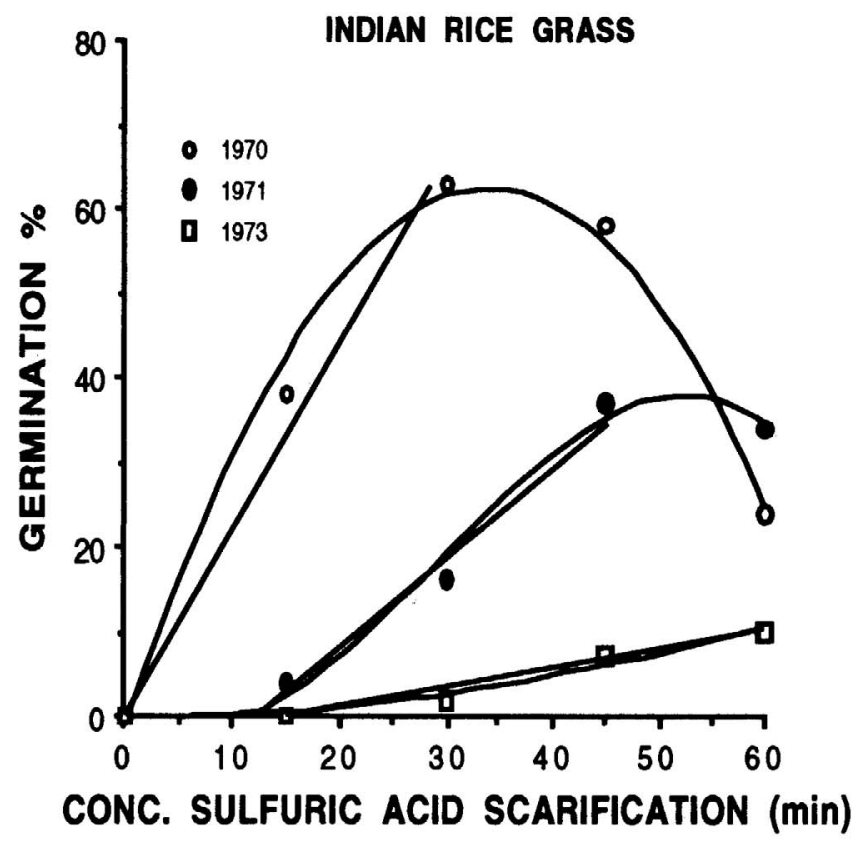

Fig. 1. Relationship between sulfuric acid scarification time and germination of Indian ricegrass seeds harvested in 1970, 1971, and 1973. Appropriate regression equations were generated to fit the data (from McDonald and Khan, 1977). 
the scarification treatment, required longer period for optimum scarification (a period beyond which seeds were adversely affected by scarification), and had lower peak germination percentage compared to the 1970 seeds. Although the linearity of the response extended over a longer period in the younger seeds, their peak germination percentage was lower than that of the older seeds, indicating that they were not only more resistant to scarification but also generated a lower embryo growth potential. The curves show that, beyond a certain time, scarification adversely affects germination, presumably as a result of acid injury to the embryo. These studies indicate that changes in embryo growth potential and seed coat strength occur during storage and both of these changes can be used to quantify dormancy.

Growth potential changes by high temperature shift and dormancy intensity. Intact or sulfuric acid scarified curly dock (Rumex crispus L.) seeds fail to germinate in darkness at 20,25 , or $30^{\circ} \mathrm{C}$. A 1-h temperature shift to $40^{\circ} \mathrm{C}$, applied at various times to scarified seeds during a dark soak at $25^{\circ} \mathrm{C}$, progressively increased the effectiveness of the shift to promote germination (Hemmat et al., 1985). Shifting at 24 h caused nearly $100 \%$ germination. The shift applied after 48 - or 72 $h$ imbibition was less effective, leading to only $75 \%$ and $45 \%$ germination, respectively (see below for reduced embryo growth potential during prolonged dark soak). A similar germination response pattern was found upon application of the $1-\mathrm{h} 40^{\circ} \mathrm{C}$ shift to intact (nonscarified) seeds soaked in darkness, but the peak gemination after the 24-h soak reached only $15 \%$. These data show that the high temperature shift permits the detection of temporal changes in the dormancy intensity or embryo growth potential during the dark soaking and is facilitated by scarification. The high-temperature shift influences a membraneassociated event that evidently is related to processes affecting embryo growth potential.

\section{ENVIRONMENTAL STIMULI}

Period of dark soak and dormancy intensity. Seeds of several species requiring light for germination are rendered progressively more dormant with increase in the dark soak time, while light or GA applied during soaking prevents dormancy induction. Seeds of 'Grand Rapids' lettuce (Lactuca sativa $\mathrm{L}$.) germinate poorly or not at all at 25 ${ }^{\circ} \mathrm{C}$. When the seeds are depericarped at $6 \mathrm{~h}$ of dark soaking, all germinate in darkness, indicating that the removal of the pericarp lowers the restraint by the covering structures to below that of the germination or growth potential needed for radicle protrusion (Khan and Samimy, 1982). However, if the seeds are depericarped after longer periods of dark soaking, a dormancy is progressively induced and after a 24-h soak even the depericarped seeds fail to germinate. Thus, the degree of dormancy induced, as evidenced by decreased growth potential, can be quantified in light-requiring seeds, based on the duration of the dark soak and the nature of the seed coat restraint. As the restraining forces of the pericarp and endosperm on the embryo are measurable (Tao and Khan, 1975), the forces needed to prevent germination are measurable.

Dark dormancy (skotodormancy) can also be released by irradiation or moist-chilling. Perennial goosefoot (Chenopodium bonushenricus $\mathrm{L}$.) seeds, for example, were made completely germinable in darkness by moist-chilling at $5{ }^{\circ} \mathrm{C}$ for 1 month. A dark soak of prechilled seeds in -0.86 MPa polyethylene glycol-6000 (PEG) solution gradually induced a dormancy and by 21 days of soaking, the seeds were rendered completely dormant (Fig. 2) (Khan and Karssen, 1980). Dormancy induction was prevented (and the rate of germination enhanced) in seeds treated with light or GA (data not shown) during the osmotic soak. Thus, a period of dark soak in an osmotic solution can be used to quantify the degree of dormancy induced in a seed with moist-chilling and light requirement.

Temporal relationship between $P_{f r}$ action and dormancy intensity. The time needed for the $\mathrm{P}_{\mathrm{fr}}$ (active form of the phytochrome) to fully act to release the dark dormancy in 'Grand Rapids' lettuce seeds is $\approx 8$ $\mathrm{h}$ at $25^{\circ} \mathrm{C}$ and is referred to as the 'escape time' from inhibition by farred irradiation (Borthwick et al., 1954; Ikuma and Thimann, 1960). If the far-red irradiation is applied immediately after red irradiation, dormancy is not released. A progressively greater release of dormancy occurs if the period between the application of red and far-red irradia- tion gradually is increased to $8 \mathrm{~h}$, when the dormancy release is complete. After $\mathrm{P}_{\mathrm{fr}}$ has acted fully to release the dormancy, its reversion to $\mathrm{P}_{\mathrm{r}}$ (inactive form of the phytochrome) by far-red is of little consequence. Thus, the time of $P_{\mathrm{fr}}$ action is a good measure of the extent of dormancy released and varies greatly among photosensitive seeds (Toole et al., 1973).

Temporal relationship between moist-chilling period and dormancy intensity. Moist-chilling or stratification at 1 to $10^{\circ} \mathrm{C}$ releases dormancy in a wide variety of seeds (Stokes, 1969). An excellent relationship was obtained between the length of chilling period and growth in pear (Pyrus communis L.) embryos excised following moist-

\section{CHENOPODIUM BONUS-HENRICUS}

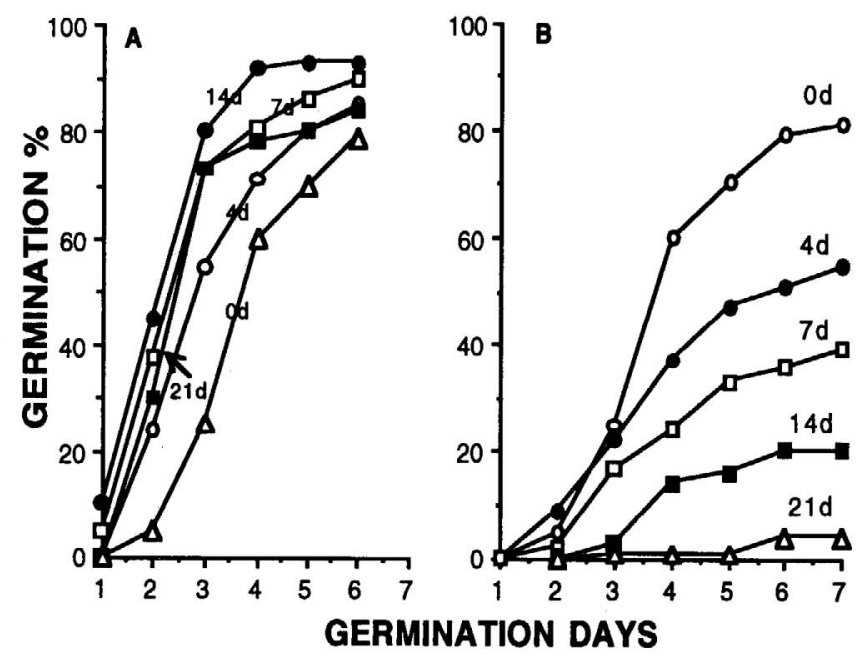

Fig. 2. Effect of various durations of (A) light and (B) dark soaking of moistchilled Chenopodium bonus-henricus seeds in - $0.86 \mathrm{MPa}$ PEG solution on (A) dormancy prevention and (B) dormancy induction, expressed as percent germination. Following the osmotic soak seeds were washed and germinated in water in darkness at $12 / 22{ }^{\circ} \mathrm{C}$ (from Khan and Karssen, 1980).

\section{PYRUS COMMUNIS (Bartlett)}

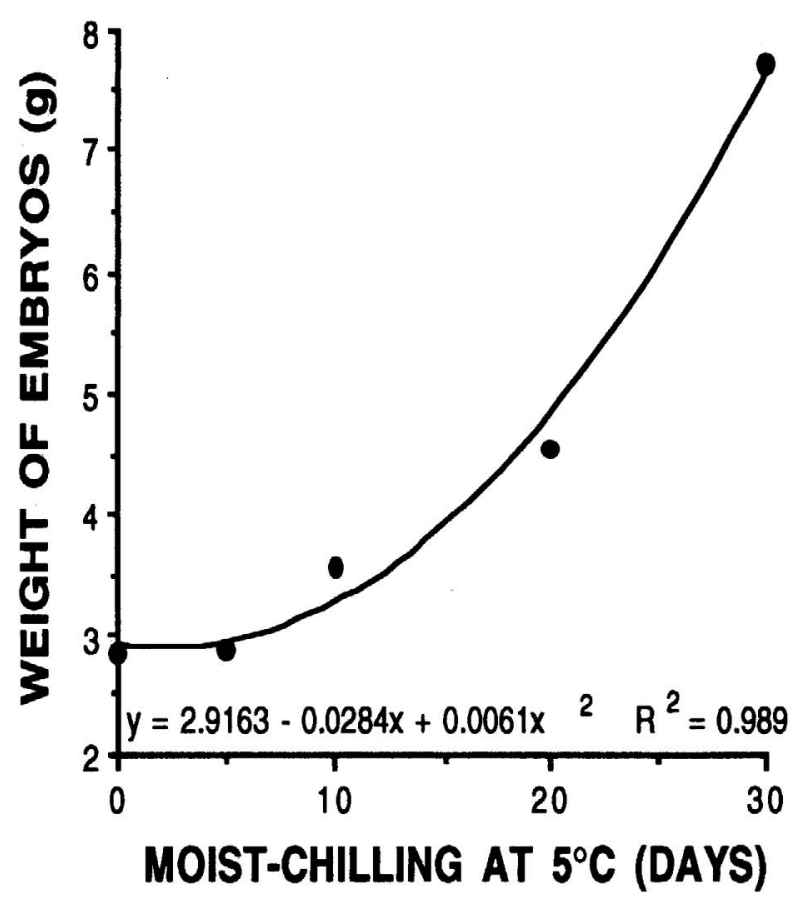

Fig. 3. Relationship between the period of moist-chilling of pear seeds and the growth, expressed as weight, of excised embryo (from Khan and Heit, 1969). 
chilling of the intact seeds at $5^{\circ} \mathrm{C}$ (Khan and Heit, 1969) (Fig. 3). Dormancy was completely released by 30 days of chilling, as no further increase in embryo growth was induced by extending the stratification period. In apple (Malus pimula L.), the time needed for the complete release of dormancy is considerably longer, usually 40 to 60 days (Lewak and Rudnicki, 1969, Singh and Browning, 1991). Duration of moist-chilling to release the dormancy of embryos is influenced by factors such as anaerobiosis, covering structures and the presence of inhibitors.

\section{HORMONAL CONTROL}

Inhibition of GA biosynthesis and dormancy intensity. GA biosynthesis inhibitors, such as tetcyclacis [5-(4-chlorophenyl)-3, 4, 5, 9, 10pentaazatetracyclo $\left[5.4 \cdot 10^{2,6} \cdot 0^{8,11}\right]$-dodeca-3,9-diene $]$, uniconazol $[(E)$ 1-(4-chlorophenyl)-4,4-dimethyl-2-( $H$ - 1,2,4-triazol-1-yl)-1-penten3-ol], paclobutrazol [1-(4-chlorophenyl )-4, 4-dimethyl-2-(1H-1,2,4triazol-1-yl)-pentan-3-ol], and ancymidol [a-cyclopropyl-a-(4methoxyphenyl)- 5-pyrimidine methanol] counteract light-promoted germination in seeds of lettuce [Arabidopsis thaliana (L.) Heyhn] and several other species (Gardner, 1983; Karssen et al., 1989; Nambara et al., 1991). These inhibitors also induce dormancy, as the seeds fail to germinate in water upon removal of the inhibitors by washing (Khan, 1994). The induced dormancy is released by GA, light or moistchilling. Inhibitors of GA biosynthesis could be used to assess the degree of dormancy induced. A dark soak of 'Mesa 659' lettuce seeds in tetcyclacis solution gradually induced a dormancy and, by $10 \mathrm{~h}$, nearly $80 \%$ of the seeds became dormant (Khan, 1994). This reaction might indicate that the monooxygenases controlling GA synthesis/ action (Rademacher, 1992) are fully inactivated by $10 \mathrm{~h}$.

In another study (Khan et al., 1992), $100 \mu \mathrm{M}$ tetcyclacis was applied during an osmotic soak of dark-germinating 'Mesa 659' lettuce seeds. The dormancy induced was progressively reduced by increasing the concentration of $\mathrm{GA}_{4+7}$ added to the osmotic solution (Fig. 4). When the GA level was higher than that of tetcyclacis, dormancy induction

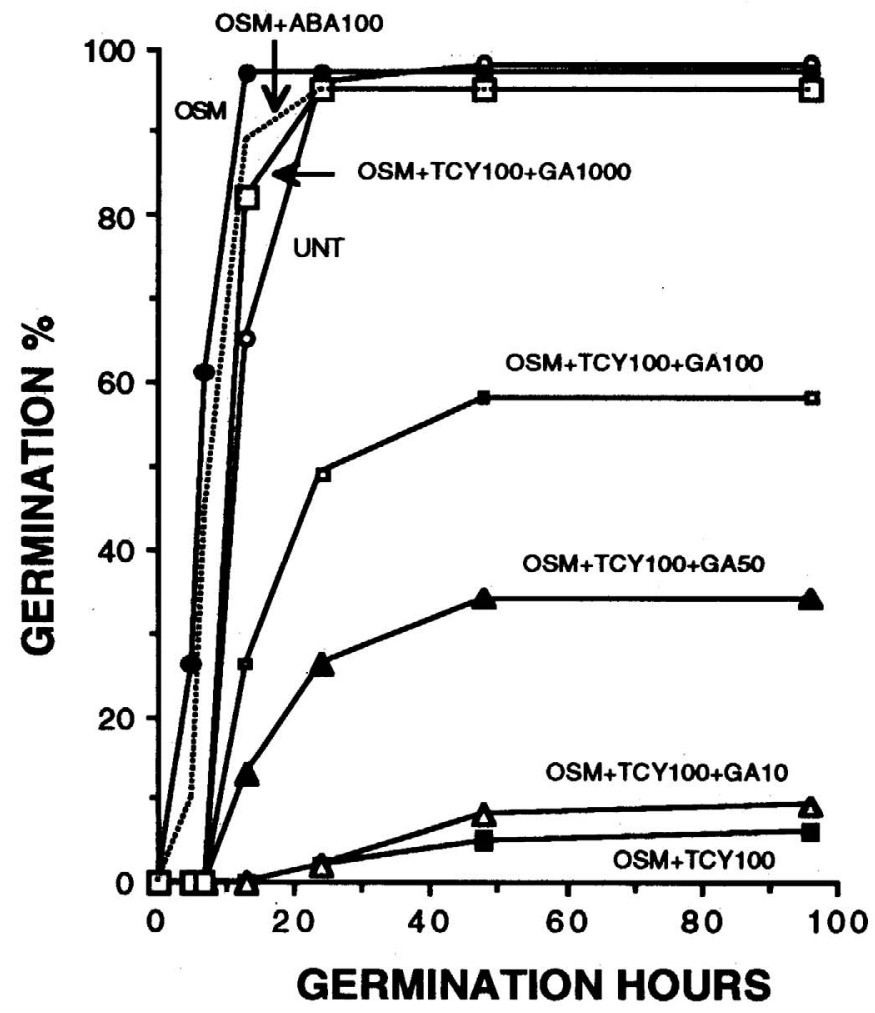

Fig. 4. Effect of tetcyclacis (TCY) and ABA on dormancy induction in 'Mesa $659^{\prime}$ lettuce seeds during a dark soak in $-1.2 \mathrm{MPa}$ PEG solution at $15^{\circ} \mathrm{C}$ and the reversal of TCY effect by progressively higher concentration of $\mathrm{GA}_{4+7}$. After the treatment, seeds were washed and germinated in water at $25^{\circ} \mathrm{C}$ in darkness. UNT $=$ untreated. OSM $=$ osmotically treated. Numbers next to chemicals refer to concentration in $\mu_{M}$ (from Khan et al., 1992). was prevented, and when the reverse was true, dormancy was induced. Unlike tetcyclacis, ABA failed to induce dormancy when added to the PEG solution. Soaking seeds in osmotic solutions of GA and GA synthesis inhibitors thus provides a convenient means to show a range of inducible or releasable dormancy states.

Inhibitors of GA biosynthesis also cause a measurable reduction in embryo growth potential. Various degrees of dormancy were induced by soaking 'Mesa 659' lettuce seeds in various concentrations of tetcyclacis (Khan, unpublished). The water potentials needed to suppress germination of these seeds were then determined by soaking them in PEG solution of progressively lower water potential. Depending upon the intensity of the induced dormancy, the embryo generated a correspondingly lower or higher growth potential (Fig. 5). For example, the water potential needed to obtain $20 \%$ germination in seeds treated with $1 \mu \mathrm{M}$ tetcyclacis was -0.57 compared to $-0.18 \mathrm{MPa}$ for seeds treated with $10 \mu \mathrm{M}$ tetcyclacis.

Escape time for GA synthesis/action and dormancy intensity. Induction of dormancy in nondormant lettuce seeds by tetcyclacis indicates that GA is synthesized during soaking (Khan, 1994). To determine if the amount of GA synthesized is related to dormancy intensity, 'Mesa 659' lettuce seeds were presoaked in water for various times followed by a 24 - $\mathrm{h}$ soak in tetcyclacis solution to induce dormancy, and then washed and germinated in water in darkness. The effectiveness of tetcyclacis to induce dormancy was gradually lost as the presoak time in water increased, and after $8 \mathrm{~h}$ of presoak, tetcyclacis was no longer effective in inducing dormancy (Khan, 1996) (Fig. 6). Thus, the time of presoak, or the "escape time" for the inhibitory effect of tetcyclacis, beyond which GA synthesis inhibition becomes inconsequential, could be used to quantify the degree of dormancy. Similar results were obtained in pepper (Capsicum annuum L.) seeds, but the time of presoak in water, beyond which tetcyclacis was ineffective in preventing dormancy, was $\approx 2$ days (Ilyas, 1994).

These data indicate that GA can be synthesized in a nondormant seed and its inhibition could lead to dormancy induction. Dormant lettuce seeds require a dormancy releasing stimulus, such as red light irradiation, initiate GA synthesis (Toyomasu et al., 1993). Interestingly, the 8-h period, the escape time for GA synthesis/action in the nondormant 'Mesa 659' lettuce seeds, is very similar to the escape time of $\mathrm{P}_{\mathrm{fr}}$ synthesis/action in the dormant 'Grand Rapids' lettuce seeds, suggesting that GA synthesis is intimately related with dormancy prevention. Light-requiring seeds, when moist-chilled or treated with GA, become highly sensitive to light (Rethy et al., 1987; Taylorson,

\section{LETTUCE SEEDS (Mesa 659)}

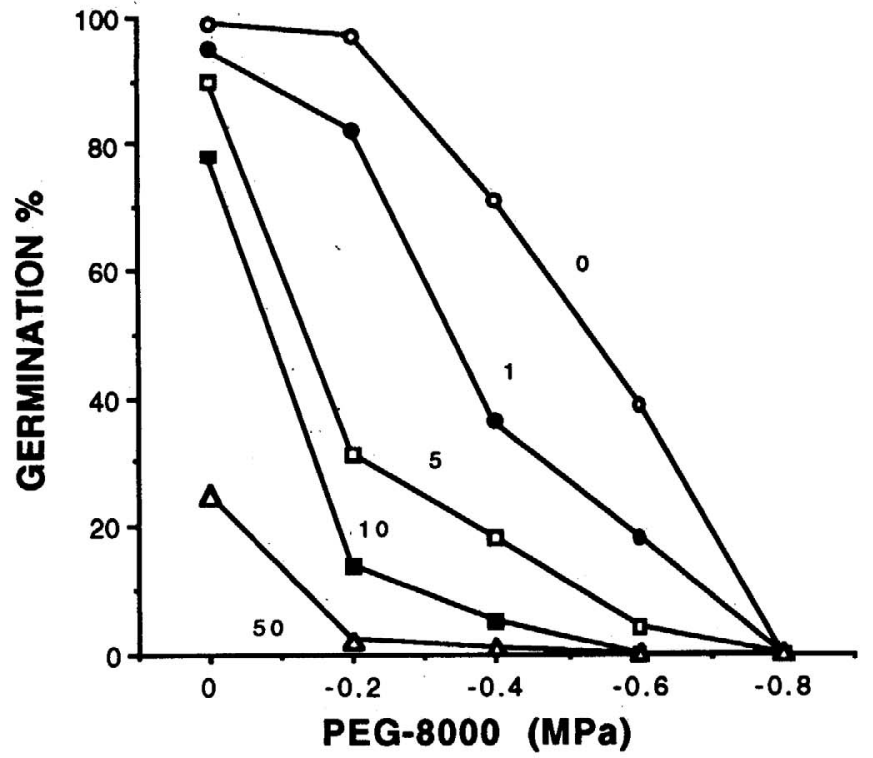

Fig. 5. Progressive reduction in embryo growth potential, expressed as percent germination, in 'Emperor' lettuce seeds by increasing concentration of tetcyclacis (TCY). Seeds were soaked in 0 to $50 \mu \mathrm{M} \mathrm{TCY}$ solution for $8 \mathrm{~h}$, washed, dried, and then germinated in PEG solutions of 0 to $-0.8 \mathrm{MPa}$ at $25^{\circ} \mathrm{C}$. All operations were conducted in darkness or green safe light. 
LETTUCE (Mosa 659)

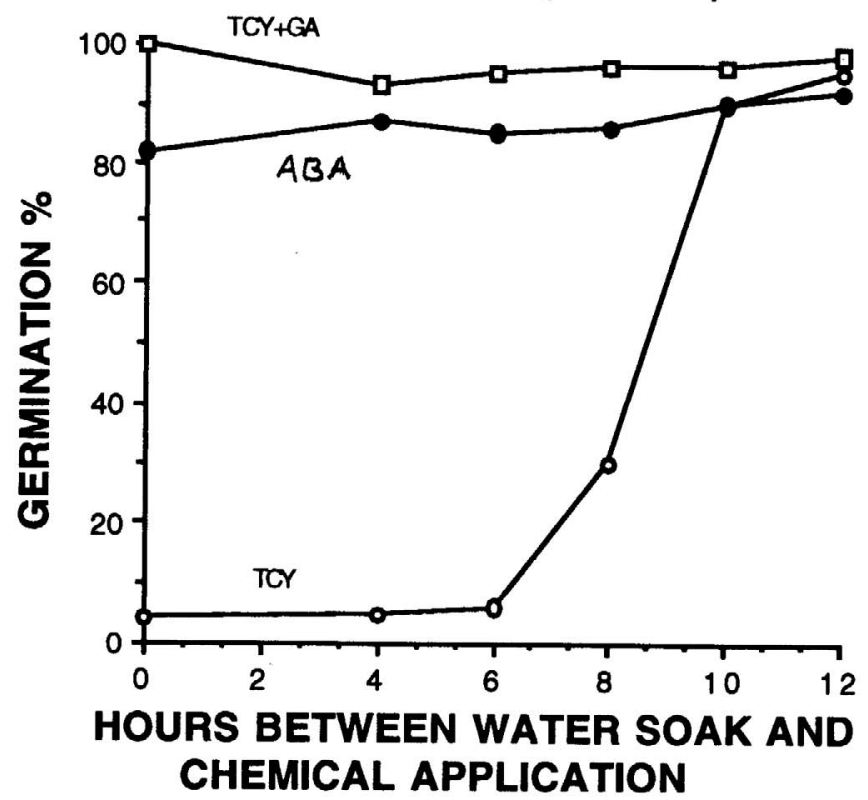

Fig. 6. Progressive increase in percent germination in 'Emperor' lettuce seeds with increase in the period between the beginning of soak and tetcyclacis (TCY) application. Seeds were soaked in water for up to $12 \mathrm{~h}$ at $25^{\circ} \mathrm{C}$, then held in $50 \mu \mathrm{M} \mathrm{TCY}, 50 \mu \mathrm{M} \mathrm{ABA}$, or $50 \mu \mathrm{M} \mathrm{TCY}+1 \mathrm{mM} \mathrm{GA}_{4+7}$ for $24 \mathrm{~h}$ at 25 ${ }^{\circ} \mathrm{C}$, and then were washed and germinated in water at $25^{\circ} \mathrm{C}$ for 10 days. All operations were conducted in darkness or green safe light (from Khan, 1996).

1982; VanDerWoude, 1989). Dormancy releasing treatments, such as these, may obviate or reduce the need for irradiation for GA synthesis. The sensitivity to tetcyclacis was greater in the 'Mesa 659' lettuce seeds germinating in darkness compared to the light-requiring 'Grand Rapids' lettuce seeds (Khan et al., 1992), suggesting a lesser requirement for GA for dormancy release in the dark-germinating seeds.

$G A_{I}$ production and dormancy intensity. $\mathrm{GA}_{1}$ production gradually increased in response to a brief exposure of red light irradiation during dark imbibition of 'Grand Rapids' lettuce seeds (Fig. 7) (Toyomasu et al., 1993). A far-red irradiation applied immediately after red irradiation inhibited $\mathrm{GA}_{1}$ production. Seeds irradiated only with far-red light failed to produce $\mathrm{GA}_{1}$. The data indicate that $\mathrm{GA}_{1}$ is produced via $\mathrm{GA}_{19}$ and $\mathrm{GA}_{20}$, the amount of which do not change upon red irradiation. These results suggest that $\beta$-hydroxylation of GA may be the initial step in the production of active GA (e.g., $\mathrm{GA}_{1}$ ) and the release of dormancy in lettuce seeds. The amount of $\mathrm{GA}_{1}$ produced during initial soaking provides a means to quantify the changes that might be associated with dormancy release. The claim that an increase in $\mathrm{GA}_{1}$ production are associated with dormancy release will be strengthened if such an increase occurs also during dormancy release in seeds made dormant by GA synthesis inhibitors.

\section{MOLECULAR CHANGES}

Enhanced RNA synthesis and dormancy intensity. Molecular changes associated with dormancy are not yet clearly understood. Several studies, however, indicate that molecular markers can be used to quantify physiological manifestations associated with the induction, maintenance and release of dormancy. $\left[{ }^{3} \mathrm{H}\right]$-uridine incorporation was increased in all RNA species (mRNA, rRNA, and sRNA) with an increase in dormancy release by moist-chilling of pear embryos (Khan and Heit, 1968) (Fig. 8). As a parallel increase in growth of excised embryos occurred, RNA synthesizing ability may be used as a biochemical marker to quantify the degree of dormancy. However, when the dormant and moist-chilled (after-ripened) embryos were imbibed at $25^{\circ} \mathrm{C}$ (germination enabling condition), the $\left[{ }^{3} \mathrm{H}\right]$-uridine incorporation into RNA increased 20- to 30 -fold during the 24-h soak in dormant embryos while decreasing in chilled embryos (Khan, 1977) (Fig. 9). The gradual increase in RNA transcripts in unchilled seeds may be

\section{LETTUCE (Grand Rapids)}

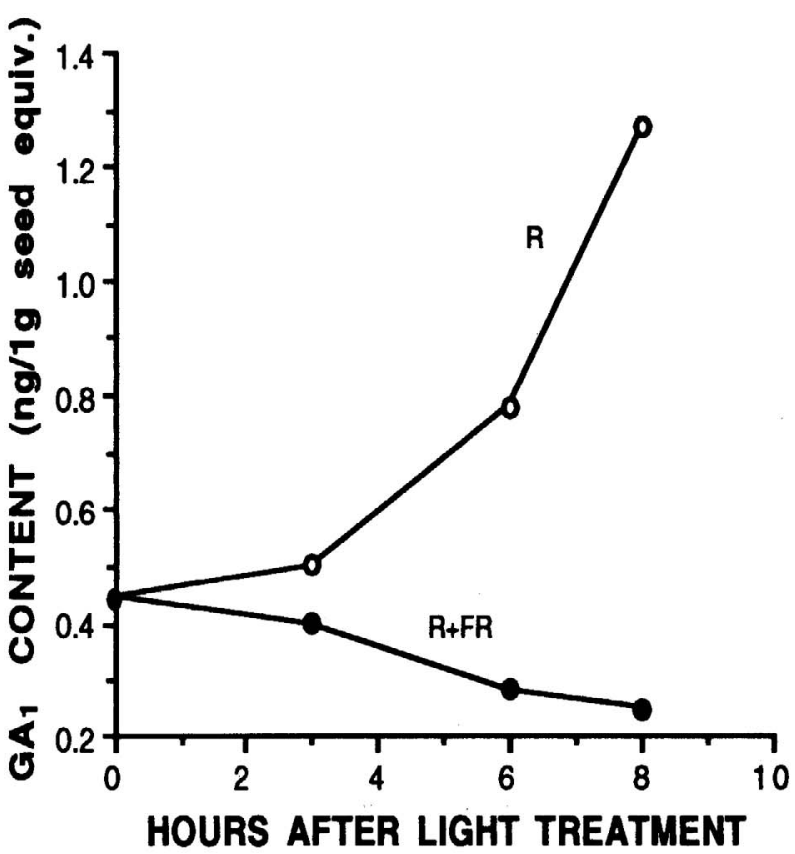

Fig. 7. Changes in $\mathrm{GA}_{1}$ content in red (R)- and red plus far red (R+FR)irradiated 'Grand Rapids' lettuce seeds. Seeds were soaked in darkness at $25^{\circ} \mathrm{C}$ and irradiated with red light for $10 \mathrm{~min}$ after a 3-h soak. A 10 -min farred irradiation followed immediately after red for seeds given $\mathrm{R}+\mathrm{FR}$. The GA content was measured by GC-SIM (from Toyomasu et al., 1993).

attributable to increased DNA template availability for these transcripts during soaking at $25^{\circ} \mathrm{C}$, unrelated to dormancy release. Thus, considerable caution is needed in interpreting RNA synthetic activities in nondormant and chilled embryos soaked for 1 to $2 \mathrm{~h}$ vs. those soaked for longer periods at temperatures supporting growth (e.g., $25^{\circ} \mathrm{C}$ ).

In vivo and in vitro protein synthesis and dormancy intensity. In a study of in vivo protein synthesis, the incorporation of $\left[{ }^{35} \mathrm{~S}\right]$-methionine into protein was greater in dormant than in the nondormant (afterripened) wild oat (Avena fatua L.) embryos incubated at $16^{\circ} \mathrm{C}$ for 8 to $36 \mathrm{~h}$ (Li and Foley, 1994). The authors suggested that increased protein synthesis may be due to increases in gene transcripts encoding proteins related to maintenance of dormancy. Similar trends in proteins synthesized in vitro were found, although no major differences in polypeptides of dormant and nondormant embryos were noted in embryos soaked $6 \mathrm{~h}$ at $16^{\circ} \mathrm{C}$.

The in vitro protein synthesizing activities of polyribosomes isolated from pear embryos increased with increasing duration of moistchilling at $5{ }^{\circ} \mathrm{C}$, indicating that more mRNA is available for protein synthesis in the chilled than in dormant embryos (Alscher-Herman et al., 1981). Maximum protein synthesis corresponded with the ability of the embryos to acquire full capacity for normal seedling development. These data suggested that protein synthesizing activity may be used to quantify dormancy intensity.

Selective gene expression and dormancy regulation. Several laboratories have constructed $\mathrm{CDNA}$ libraries from embryonic poly $(\mathrm{A})^{+}$ RNAs of seeds and have differentially screened the cDNA clones for mRNAs abundant in dormant (or ABA-treated) and nondormant (or GA or red light-treated) tissues. Several attempts have been made to relate the increase/decrease in the gene transcripts to events associated with dormancy maintenance and dormancy release or germination (Goldmark et al., 1992; Hong et al., 1992; Li and Foley, 1995; Morris et al., 1991; Toyomasu et al., 1995).

The fact that the transcripts of certain genes (e.g., clone pBS128 in Bromus secalinus L.) in embryos of Bromus and of several clones of wild oat are maintained or increased in dormant embryos or nondormant embryos treated with $\mathrm{ABA}$ or high temperature for a relatively short duration, and that they decrease in nondormant or GA-treated embryos (Goldmark et al., 1992; Li and Foley, 1994) is not a definitive proof for their involvement in dormancy regulation. The increase in 
PEAR (Bartlett)

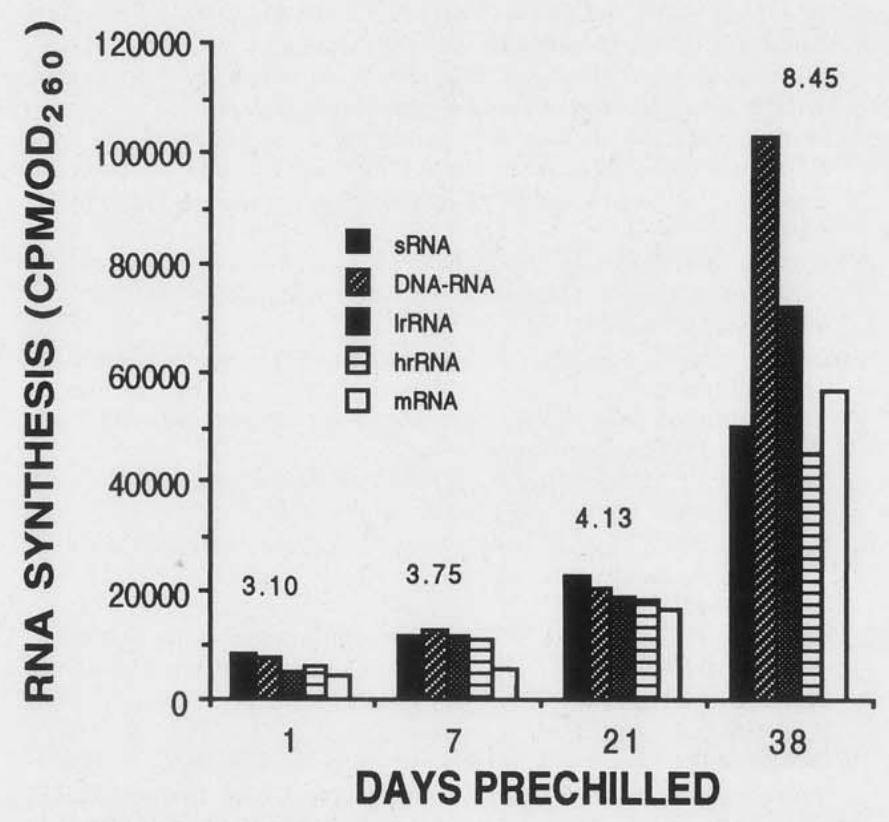

Fig. 8. Increase in the synthesis of various RNA species in pear embryos excised from seeds moist-chilled for 1 to 38 days at $5{ }^{\circ} \mathrm{C}$. The corresponding increase in fresh weight ( $\mathrm{mg}$ ) of embryos, grown for 4 days, is indicated for each prechilling period (from Khan and Heit, 1968).

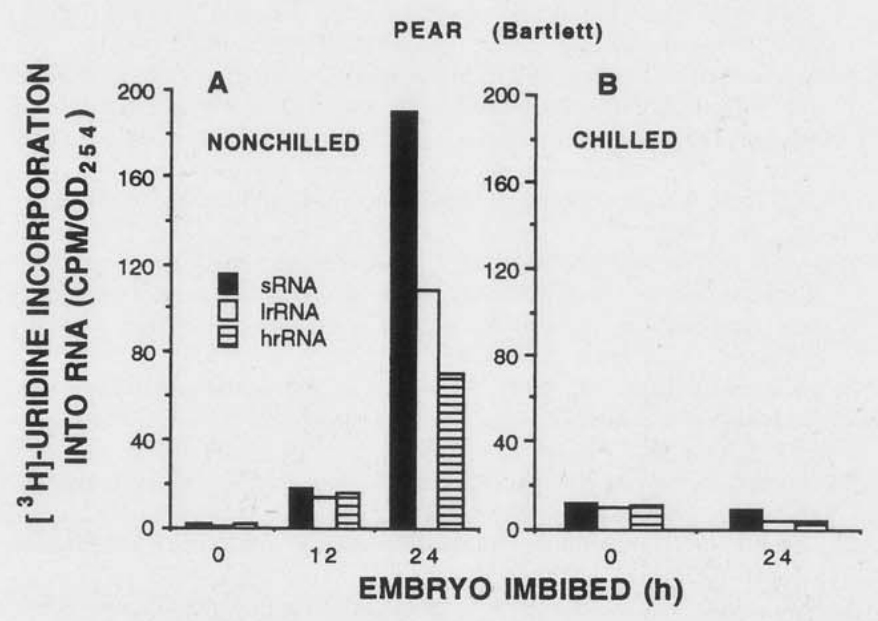

Fig. 9. Comparison of RNAs transcribed by moist-chilled and nonchilled embryos at 0,12 , and $24 \mathrm{~h}$ of soaking at $25^{\circ} \mathrm{C}$. Moist-chilled embryos were excised from pear seeds soaked at $5^{\circ} \mathrm{C}$ for 42 days. Nonchilled embryos were excised from seeds after a 24 -h soak at $25^{\circ} \mathrm{C}$ (from Khan, 1977).

transcripts attributed to dormancy maintenance in nonafterripened or ABA-treated embryos could conceivably be an expression of growth inhibition or an inhibitory state of the embryo unrelated to dormancy; and, the disappearance of these transcripts may be a result of the removal of the inhibitory block, unrelated to the relief of dormancy. Lack of ABA participation in dormancy control is indicated from several studies. Short-duration treatments with ABA or other stressful factors (e.g., high temperature, low water potential) do not induce dormancy in many cases (Khan, 1994, 1996). Dormancy can be induced in seeds deficient in ABA (Hilhorst and Karssen, 1992), and $\mathrm{ABA}$ levels or sensitivity to ABA in dormant and nondormant embryos do not always differ (Goldmark et al., 1993; Leon-Kloosterziel et al., 1996).

Toyomasu et al. (1995) recently identified two cDNA clones, LRG5 and LRG11, from 'Grand Rapids' lettuce seeds that responded to GA and red light by increasing the transcript levels of these genes during dormancy release prior to germination but the amounts (radio-
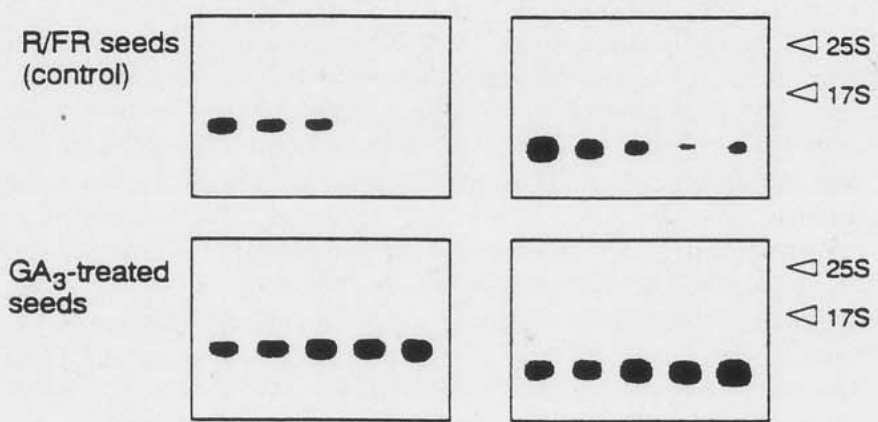

$R$ seeds
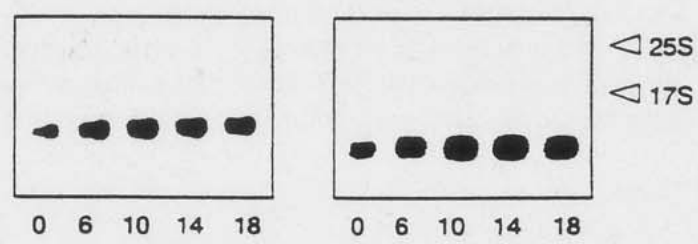

\section{HOURS AFTER TREATMENT}

Fig. 10. Changes in mRNA transcripts of cDNA clones LRG5 and LRG11 by red irradiation $(\mathrm{R})$, red plus far-red irradiation $(\mathrm{R} / \mathrm{FR})$, or by $\mathrm{GA}_{3}$ treatment of 'Grand Rapids' lettuce seeds during early soaking. After each soak time, total RNA was extracted and hybridized with the $\left[{ }^{32} \mathrm{P}\right]$-labeled cDNA clone used as a probe. The increase or decline in the amount of mRNA transcript (transcript level) corresponding to each clone was quantified by radioanalytic imaging (from Toyomasu et al., 1995).

active label) decreased in the dormant or untreated seeds (Fig. 10). The gradual increase in the gene transcripts in the GA or red-light-treated lettuce seeds coincided with the increase in the amount of $\mathrm{GA}_{1}$ (Toyomasu et al., 1993) and with the escape time $(8 \mathrm{~h})$ for the inhibitory effects of far red irradiation (Borthwick et al., 1954) and GA synthesis inhibitors (Khan, 1994) on dormancy release. This interesting finding suggests that GA-stimulated increase in the gene transcripts may be associated with the events releasing dormancy and that lack of an increase or a decrease in the transcripts may be associated with the maintenance and intensification of dormancy. Thus, it may be possible to quantify dormancy release, induction, and intensification by following the temporal increases or decreases in the transcripts of genes in response to dormancy releasing and preventing agents.

\section{CONCLUSIONS}

Dormancy induction, maintenance, and release are commonly observed in mature or near-mature seeds. Examples of dormancy quantification, drawn from various studies, indicate that the release, induction, or intensification of dormancy can be quantified in terms of growth potential changes (often expressed as embryo growth or germination), variations in seedcoat strength, the time-dependent increases or decreases in the responsivenéss to environmental and chemical stimuli, and changes in GA amounts and action. An effort to quantify dormancy at the molecular level in terms of gene expression has given mixed results. Much effort has been directed at studying the gene transcripts and gene products that are responsive to $\mathrm{ABA}$ and other stress factors. The increase in gene transcripts provoked by these factors may be an expression of growth inhibition unrelated to dormancy induction. One difficulty in quantifying dormancy at the biochemical and molecular level may be the inability to easily separate changes due to germination inhibition from those related to dormancy induction. Similarly, no distinction has been made in molecular studies between dormancy release and germination or stress alleviation.

Dormancy induction/release is a reversible process and occurs under stressful and nonstressful conditions and appears to involve receptor cites on the membranes. Dormancy may be released by applying GA or by factors that mimic or produce GA, such as irradiation, moist-chilling, dry-afterripening, a brief high-temperature 
shift, etc. No "triggering" treatment may be needed for nondormant seeds (or for dormant seeds whose dormancy has been released) to initiate GA production (Khan, 1994; Khan, unpublished). If GA is not able to act for a defined period, the so-called escape time for the induction of dormancy, or if its production is halted at the start or midway during this period, the seeds can become wholly or partially dormant (Khan, 1994). Thus, the GA produced not only releases the dormancy but also ensures that the seeds do not become dormant.

The enhanced responsiveness of certain genes in the presence and the reduced responsiveness in the absence of GA may serve to quantify dormancy release and induction in seeds. This situation may be true in buds as well. For example, a temporal sequence in the expression of an invertase gene in Jerusalem artichoke (Helianthus tuberosus L.) tubers (Venuat et al., 1993) and a ribosomal protein gene in pea (Pisum sativum L.) axillary buds (Stafstrom and Sussex, 1993) was observed by treatments releasing dormancy. A clear understanding of the physical/physiological bases for the separation of the dormancy induction/release process from germination inhibition/germination enabling stress-related process is needed to quantify dormancy in molecular terms.

\section{Literature Cited}

Alscher-Herman, R., M. Musgrave, A.C. Leopold, and A.A. Khan. 1981. polyribosomes and protein synthesis in after-ripening pear seeds. Physiol. Plant. 48:285-291.

Borthwick, H.A., S.B. Hendricks, E.H. Toole, and V.K. Toole. 1954. Action of light on lettuce seed germination. Bot. Gaz. 115:205-225.

Gardner, G. 1983. The effect of growth retardants on phytochrome-induced lettuce seed germination. J. Plant Growth Regulat. 2:159-163.

Goldmark, P.J., J. Curry, C.F. Morris, and M.K. Walker-Simmons. 1992. Cloning and expression of an embryo-specific mRNA up-regulated in hydrated dormant seeds. Plant Mol. Biol. 19:433-441.

Hemmat, M., G.W. Zeng, and A.A. Khan. 1985. Responses of intact and scarified curly dock (Rumex crispus) seeds to physical and chemical stimuli. Weed Sci. 33:658-664.

Hilhorst, H.W.M. and C.M. Karssen. 1992. Seed dormancy and germination: the role of abscisic acid and gibberellins and the importance of hormone mutants. Plant Growth Regulat. 11:225-238.

Hong, B., R. Barg, and T-H.D. Ho. 1992. Developmental and organ-specific expression of an ABA-and stress-induced protein in barley. Plant Mol. Biol. 18:663-674.

Ikuma, H. and K.V. Thimann. 1960. Action of gibberellic acid on lettuce seed germination. Plant Physiol. 35:557-566.

Ilyas, S. 1993. Invigoration of pepper (Capsicum annuum L.) seed by matriconditioning and its relationship with storability, dormancy, stress tolerance and ethylene biosynthesis. PhD Thesis, Cornell Univ.

Karssen, C.M., S. Zagorski, J. Kepczynski, and S.P.C. Groot. 1989. Key role for endogenous gibberellins in the control of seed germination. Ann. Bot. 63:71-80.

Khan, A.A. 1971. Cytokinins: Permissive role in seed germination. Science 171:853-859.

Khan, A.A. 1977. Seed dormancy: changing concepts and theories, p. 29-50. In: A.A. Khan (ed.). The physiology and biochemistry of seed dormancy and germination. Elsevier/North Holland Biomedical Press, Amsterdam.

Khan, A.A. 1994. Induction of dormancy in nondormant seeds. J. Amer. Soc. Hort. Sci. 119:408-413.

Khan, A.A. 1996. Control and manipulation of seed dormancy, p. 29-45. In: G.A. Lang (ed.). Plant dormancy: Physiology, biochemistry and molecular biology. CAB Intl., Wallingford, U.K.

Khan, A.A. and C. Andreoli. 1993. Hormonal control of seed dormancy and germination under stressful and nonstressful conditions, p. 625-632. In: D. Come and F. Corbineau (eds.). Fourth Intl. Workshop on Seeds. Basic and applied aspects of seed biology. vol. 2. ASFIS, Paris, France.

Khan, A.A. and C.E. Heit. 1969. Selective effects of hormones on nucleic acid metabolism during germination of pear embryos. Biochem. J. 113:707712.

Khan, A.A., C.E. Heit, and P.C. Lippold. 1968. Increase in nucleic acid synthesizing capacity during cold treatment of dormant pear embryos. Biochem. Biophys. Res. Commun. 33:391-396.

Khan, A.A. and X.-L. Huang. 1988. Synergistic enhancement of ethylene production and germination with kinetin and 1-aminocyclopropane-1- carboxylic acid in lettuce seeds exposed to salinity stress. Plant Physiol. $87: 847-852$.

Khan, A.A., X.-L. Huang, G.-W. Zeng, and J. Prusinski. 1992. Integration of hormonal controls of seed dormancy and germination with environmental demands, p. 313-335. In: J.-R. Fu and A. A. Khan (eds.). Advances in the science ànd technology of seeds. Science Press, Beijing.

Khan, A.A. and C.M. Karssen. 1980. Induction of secondary dormancy in Chenopodium bonus-henricus $\mathrm{L}$. seeds by osmotic and high temperature treatments and its prevention by light and growth regulators. Plant Physiol. 66:175-181.

Khan, A.A. and J. Prusinski. 1989. Kinetin enhanced 1-aminocyclopropane-1carboxylic acid utilization during alleviation of high temperature stress in lettuce seeds. Plant Physiol. 91:733-737.

Khan, A.A. and C. Samimy. 1982. Hormones in relation to primary and secondary dormancy, p. 203-241. In: A. A. Khan (ed.). The physiology and biochemistry of seed development, dormancy and germination. Elsevier Biomedical Press, Amsterdam.

Le Page-Degivry, M. In situ abscisic synthesis. A requirement for induction of embryo dormancy in Helianthus annuus. Plant Physiol. 98:1386-1390.

Leon-Kloosterziel, K.M., G.A. van de Bunt, J.A.D. Zeevaart, and M. Koornneef. 1996. Arabidopsis mutants with a reduced seed dormancy. Plant Physiol. 110:233-240.

Lewak, S. and R.M. Rudnicki. 1977. After-ripening in cold requiring seeds, p. 193-217. In: A.A. Khan (ed.). The physiology and biochemistry of seed dormancy and germination. Elsevier/North-Holland Biomedical Press, Amsterdam.

Li, B. and M.E. Foley. 1994. Differential polypeptide patterns in imbibed dormant and after-ripened Aven a fatua embryos. J. Expt. Bot. 45:275-279.

Li, B. and M.E. Foley, 1995. Cloning and characterization of differentially expressed genes in imbibed dormant and afterripened Avena fatua embryos. Plant Mol. Biol. 29:823-831.

McDonald, M.B. and A.A. Khan, 1977. Factors determining germination of Indian ricegrass seeds. Agron. J. 69:558-563.

Morris, C.F., R.J. Anderberg, P.J. Goldmark, and M.K. Walker-Simmons. 1991. Molecular cloning and expression of abscisic acid-responsive genes in embryos of dormancy wheat seeds. Plant Physiol. 95:814-821.

Nambara, E., T. Akazawa, and P. McQuort. 1991. Effects of the gibberellin biosynthetic inhibitor uniconazol on mutants of Arabidopsis. Plant Physiol. 97:736-738.

Rademacher, W. 1991. Biochemical effects of plant growth retardants, p. 168200. In: H.W. Gausman (ed.). Plant biochemical regulators. Marcel Dekker, Inc., New York.

Rethy, R., A. Dedonder, E. De Petter, L. Van Wiemeersch, H. Fredericq, J. De Greef, H. Stevaert, and H. Stevans. 1987. Biphasic fluence response curves for phytochrome-mediated Kalanchoe seed germination sensitized by gibberellic acid. Plant Physiol. 83:126-130.

Singh, Z. and G. Browning, 1991. The role of ABA in the control of apple seed dormancy re-appraised by combined gas chromatography-mass spectrometry. J. Expt. Bot. 42:269-275.

Stafstrom, J.P. and I.M. Sussex. 1993. Expression of a ribosomal protein gene in axillary buds of pea seedlings. Plant Physiol. 100:1494-1502.

Stokes, P. 1965. Temperature and seed dormancy. Encyclop. Plant Physiol. 15:746-803.

Tao, K.L. and A.A. Khan. 1979. Changes in strength of lettuce endosperm during germination. Plant Physiol. 63:126-128.

Taylorson, S.B. 1982. Interaction of phytochrome and other factors in seed germination, p. 323-346. In: A.A. Khan (ed.).The physiology and biochemistry of seed development, dormancy and germination. Elsevier Biomedical Press, Amsterdam.

Toole, V.K. 1973. Effects of light, temperature and their interactions on the germination of seeds. Seed Sci. Technol. 1:339-396.

Toyomasu, T., H. Tsuji, H. Yamane, M. Nakayama, I, Yamaguchi, N. Murofushi, N, Takahashi, and Y. Inoue. 1993. Light effects on endogenous levels of gibberellins in photoblastic lettuce seeds. J. Plant Growth Regulat. 12:8590.

Toyomasu, T., T. Yamaguchi, H. Yamane, N. Murofushi, and Y. Inoue. 1995. cDNA cloning and characterization of gibberellin-responsive genes in photoblastic lettuce seeds. Biosci. Biotech. Biochem. 59:1846-1849.

VanDerWoude, W. 1989. Phytochrome and sensitization in germination control, p. 181-189. In: R.B. Taylorson (ed.). Recent advances in the development and germination of seeds. Plenum Press, New York.

Venuat, B., P. Goupil, and G. Ledoigt. 1993. Molecular cloning and physiological analysis of an invertase isoenzyme in Helianthus tissues. Biochem. Mol. Biol. Internat. 31:955-966. 